\title{
Explicit reasoning, creativity and co-construction in primary school children's collaborative activities
}

\author{
Sylvia Rojas-Drummond ${ }^{\mathrm{a}, *}$, Nancy Mazón ${ }^{\mathrm{a}}$, Manuel Fernández ${ }^{\mathrm{b}}$, Rupert Wegerif ${ }^{\mathrm{c}}$ \\ ${ }^{a}$ National Autonomous University of Mexico (UNAM), Faculty of Psychology, Av. Universidad 3004, Col. Copilco-Universidad 04510, \\ Delegación Coyoacán, México D.F., Mexico \\ ${ }^{\mathrm{b}}$ North Regional Committee for Cooperation with UNESCO, Zaragoza 1300 Sur, Edif. Kalos A2-235, 64000 Monterray, NL, Mexico \\ ${ }^{c}$ School of Education and Lifelong Learning, The University of Exeter, St. Luke's Campus, Heavitree Road, Exeter, Ex1 2LU, UK
}

Received 26 May 2006; accepted 6 June 2006

Available online 14 August 2006

\begin{abstract}
This paper describes research that explored the question of whether or not it is possible to characterise and teach a single type of educationally productive talk. We analysed and compared the quality of children's interactional strategies when jointly working on a reasoning task and a psycholinguistic task. The latter involved writing an integrated summary of three related texts. Sixth grade primary school children (11-12 years old) solved these two tasks as pre- and post-tests before and after training in the use of 'Exploratory Talk' (ET) to think together and argue as well as in strategies for producing summaries. After training, children improved substantially in the use of ET when solving the reasoning but not the psycholinguistic task. However, using ethnography of communication methods to analyse the talk further around the latter task revealed that both the number and quality of communicative events and acts increased importantly. These changes were accompanied by a significant improvement in the quality of the summaries produced. These findings suggest that the requirement for explicit reasoning in the definition and analysis of ET may be task dependent. To account for the common features of the educationally productive talk in the two settings, we propose the more inclusive concept of co-constructive talk to characterise the inter-subjective orientation, social ground rules and communicative actions that support effective collaboration, co-ordination and creativity.
\end{abstract}

(C) 2006 Elsevier Ltd. All rights reserved.

Keywords: Oracy; Exploratory talk; Co-construction; Reasoning; Creativity; Collaboration; Intervention educational programme

\section{Introduction}

The central question that we try to answer in this paper is whether or not it is possible to characterise productive educational talk in general, and for tasks of different nature, or is the quality of talk too closely related to the task for such an attempt to be useful? To pursue this question, we investigated the role of language for the social construction of knowledge in different educational contexts. Knowledge can be conceptualised as the product of the joint negotiation of the participants to make sense of a given situation, using a variety of communicative strategies to construct a shared understanding. In this respect, our study had two main purposes. On the one hand, we analysed and compared the quality of the interactional strategies children used for working and discussing in small groups in order to solve two

\footnotetext{
* Corresponding author.

E-mail address: silviar@ servidor.unam.mx (S. Rojas-Drummond).
} 
distinct types of problems. The first corresponded to a reasoning task and the second to a psycholinguistic task. On the other hand, we tested the adequacy of two different approaches to the analysis of discourse to account for the way children constructed knowledge jointly when solving these two tasks. The first approach corresponds to the method for analysing 'exploratory talk' developed by Mercer, Wegerif, and Dawes (1999). The second approach corresponds to the ethnography of communication as proposed by Hymes (1974) and Saville-Troike (2003).

\subsection{Antecedents-oracy}

Taking the sociocultural perspective that language is the main cultural tool for constructing knowledge (e.g. Mercer, 1995, 2000; Säljö, 1997; Vygotsky, 1978, 1987), the study of oral communication becomes relevant in order to account for the quality of such knowledge. Moreover, language is not only central to social interaction, but it is also constitutive of institutional and academic discourses which are re-created, transformed, and even rejected in everyday classroom activities (e.g. Gee, 1999; Hicks, 1995; Wertsch, 1998).

One way in which discourse has been studied as part of an intervention programme informed by a sociocultural perspective is the use of language for thinking together characterised as 'exploratory talk'. When participants use this type of talk, they give and provide reasons and take turns for speaking and asking all the members of a group to participate and reach joint agreements. In this respect, the reasoning is visible in the talk of the participants.

A research project in the early 1990s collected more than $50 \mathrm{~h}$ of video-recordings of children discussing together in groups to solve problems around computers. To characterise their talk, the researchers categorised it into three types, which Mercer (1995, p. 104) described as different 'social modes of thinking'. A full account of these types of talk, supported by illustrative transcripts, was given by Mercer (1995) and a version of this can be found in Wegerif and Mercer (1997). Here, for reasons of space, the three types of talk are described more briefly. Abstracting greatly from Mercer and Wegerif's account, these three types are:

- Cumulative talk: in which speakers build positively but uncritically on what the other has said;

- Disputational talk: characterised by disagreement and individualised decision making; and

- Exploratory talk: in which partners engage critically but constructively with each other's ideas.

Wegerif and Mercer (1997) apply Habermas's theory of Communicative Action (e.g. Habermas, 1981, 1990) to argue that these 'social modes of thinking' describe fundamental orientations that participants in dialogue can take towards each other. While this characterisation of talk was inspired by conceptual analysis, it was also influenced by direct empirical research and by the findings on effective collaborative learning reported in the literature (summarised in Wegerif \& Mercer, 1996), particularly the work of Kruger (1993) and Light, Littleton, Messer, and Joiner (1994). At the same time, pioneer work by Mercer and Wegerif (e.g. Mercer et al., 1999; Wegerif, Mercer, \& Dawes, 1999) found that exploratory talk could be successfully enhanced in British primary school children and that this promotion had a very positive effect on children's group and individual problem solving, as well as in performance in academic areas such as Mathematics and Science (see also Rojas-Drummond \& Mercer, 2003). The programme for promoting exploratory talk can be found in Dawes, Mecer, and Wegerif (2000).

Following these pioneer studies, research in Mexico by Rojas-Drummond et al. (e.g. Rojas-Drummond \& Peón, 2004; Rojas-Drummond, Pérez, Vélez, Gomez, \& Mendoza, 2003) have confirmed that exploratory talk can be very effective in promoting children's capacity for collaboration, for group and individual reasoning and problem-solving, as well as for argumentation. In the present study we further analysed, promoted and compared the use of exploratory talk for collaborating and solving problems in tasks related to the reasoning and psycholinguistic domains.

\subsection{General characteristics of the study}

\subsubsection{Participants}

From an original sample of 120, 10 and 11 year old children (60 experimental and 60 control), who participated in a larger study for analysing and promoting reasoning and psycholinguistic abilities related to oracy and literacy (see Mazón, Rojas-Drummond, \& Vélez, 2005), we selected randomly a much smaller sample. This was done in order to compare in greater detail the children's interactional and discursive strategies when solving two types of tasks. Firstly, for studying reasoning abilities, a microgenetic analysis of the children's discourse was performed by selecting 
randomly eight triads (four experimental and four control). Each triad solved a modified version of the Raven's Standard Progressive Matrices test (RSPM) (see Section 1.2.3). Secondly, for studying psycholinguistic abilities, four triads were randomly selected further (two experimental and two control) from the eight triads who solved the reasoning task. These four triads were administered a 'group test of textual integration' (see Section 1.2.3), in order to carry out a more thorough, small scale ethnographic analysis of the discourse used by each triad during the literacy events in which they were jointly constructing a summary.

\subsubsection{Setting}

The research was carried out in two public primary schools located in the south of Mexico City. One school, named 'experimental', was exposed to an educational programme called 'Learning Together' (described briefly below), while the other served as a control. They were equivalent in socioeconomic status and very nearby. The RSPM test was administered to the eight triads previously selected in an isolated room of each school, one triad at a time, and they were video-taped. Similarly, the four triads previously selected solved the 'group test of textual integration' following the same procedures as for the former task. The educational programme 'Learning Together' was implemented only in the experimental school, in a multipurpose classroom especially designed for the purposes of the study, with modular furniture for collaborative work; computers and an equipped small library (see Section 1.2.4 below).

\subsubsection{Materials}

We administered two tests to the children:

(a) One test corresponded to a modified version of the Raven's Standard Progressive Matrices test (RSPM) (form B), following Wegerif (1996). This consisted of a shorter version of the original test by dividing the adjacent problems into either form A or B (half in size-30 problems each), which were equivalent in degree of difficulty. We used form $\mathrm{B}$ as a small-group test where children discussed in triads to answer jointly each problem, in order to assess their use of exploratory talk.

(b) The second corresponded to a 'group test of textual integration'. This consisted of presenting each of the four selected triads with three short texts with different linguistic registers: one was taken from a real newspaper report, another one corresponded to a note from an encyclopaedia and a third one consisted of a brief interview taken from a magazine. These three texts were related in content, given that all of them talked about the healing properties of dolphins. Each triad was asked to read the three notes and discuss them to construct jointly a summary integrating the main ideas from these three sources. They were also encouraged to write an original title for their integrated summary (in this paper, we will only report a sample of the results for the oral part of the test, and will then briefly summarise the results obtained for the written part for the original sample of 120 children; the latter results are reported more thoroughly in Mazón et al., 2005).

\subsubsection{Procedures}

Following a pre-post-intervention control design, we first administered the small-group version (B) of the RSPM test to the eight triads previously selected, as described above. Secondly, we administered the 'group test of textual integration' to the four triads selected, also as described above. For the two tasks, the same version was applied as preand post-tests before and after intervention to the experimental group. We then analysed each video-recording of the interaction of each triad solving each task in detail and transcribed their talk verbatim, together with a description of the relevant context which surrounded the talk. We carried out these activities following the procedures developed by Edwards and Mercer (1987).

As part of the larger study, between the administrations of the tests, we implemented the programme 'Learning Together' to the 60 children from the experimental school, while the 60 children from the control school followed their regular classes. Briefly, throughout the programme children were encouraged to carry out a variety of collaborative activities which aimed at promoting, among other abilities, the use of exploratory talk for discussing and solving problems effectively, the construction of summaries after reading expository texts, as well as the production of more complex texts such as illustrated conferences (for a more thorough description of the programme, see Mazón et al., 2005). 


\subsection{Results for the raven's test}

We started with the general interest of studying how language was used by primary school children to solve reasoning problems jointly and how this language might change as a result of our intervention programme. In order to analyse the type of talk children used during the pre- and post-tests of the RSPM test, we characterised the talk of each triad for each Raven's problem as mainly disputational, cumulative, or exploratory, using the criteria described in Section 1 (for a more complete description of the criteria used to characterise each type of talk, see Rojas-Drummond et al., 2003).

In Table 1, we present an example of two transcripts from the dialogues produced by one triad while they solved one matrix of the RSPM test (Matrix E 7), first during the pre-test (left side) and then during the post-test (right side) (refer to Matrix E 7 of the Raven's test).

As can be seen from the transcripts, in the pre-test (left side) these children did not explore in detail the different options which might be a correct response to the matrix. They just proposed briefly several options, but without giving reasons for each selection. The option they finally chose was incorrect. The talk used by the triad was mainly cumulative.

In contrast, in the transcript from the post-test (right side), we can see how the same children explored in detail several options for choosing the answer corresponding to this matrix. They provided reasons by making use of the word 'because' in five occasions, and they negotiated different perspectives making their reasoning visible in the talk. At the same time, they jointly made sense of the problem, reached a joint conclusion and identified correctly the right answer. They used exploratory talk. Although the change in the quality of the talk from the pre- to the post-test seems very clear in the above examples, it would be valid to ask: how representative is this change for the sample of the 24 children (eight triads) that were filmed? We next present a summary of the main results obtained when comparing the use of exploratory talk in the pre- and post-tests, between the experimental and control groups (four triads per group).

The control group solved only $19 \%$ of problems using exploratory talk during the pre-test and $21 \%$ during the posttest. So they did not vary noticeably between tests. The rest of their talk (around 80\%) was mainly cumulative in both tests. In contrast, the experimental group solved 38\% of the problems through exploratory talk during the pre-test and they increased to $76 \%$ (double the amount) during the post-test. In addition, we found that the control group used a total

Table 1

Example of dialogues produced by one triad while solving Matrix E 7 during pre- and post-test

\begin{tabular}{|c|c|}
\hline Pre-test (Matrix E 7) & Post-test (Matrix E 7) \\
\hline $\begin{array}{l}\text { (1) Irving: It can be this one, no? (points to option 4) } \\
\text { (2) Heliot: Let me see } \\
\text { (3) Irving: This one (points to option 4) } \\
\text { (4) Denis: This one (points to option 7) } \\
\text { (5) Irving: This one, or not? } \\
\text { (6) Heliot: No, it has to be more } \\
\text { (7) Irving: This one (points to option 6) } \\
\text { (8) Heliot: Number six } \\
\text { (9) Irving: This is number six } \\
\text { (10) Denis: Number six } \\
\text { (11) Heliot: Ok (writes option 6-incorrect) }\end{array}$ & $\begin{array}{l}\text { (12) Heliot: It would be a triangle } \\
\text { (13) Irving: No, search further } \\
\text { (14) Heliot: A square } \\
\text { (15) Irving: A square, but } \\
\text { (16) Denis: Ok, this one } \\
\text { (17) Irving: No, yes } \\
\text { (18) Denis: A triangle } \\
\text { (19) Irving: It would be this one (pointing to option 7) because look, this is not here } \\
\text { (20) Heliot: No, but it wouldn't be this one (pointing to option 4) because look, look } \\
\text { (21) Irving: Which one? } \\
\text { (22) Heliot: Here it is repeated twice, one, two, one, two and here, which one would go? } \\
\text { (23) Irving: This one (pointing to option 7) } \\
\text { (24) Heliot: This one (pointing to option 4) } \\
\text { (25) Denis: No } \\
\text { (26) Irving: No, because if you notice they have a different figure } \\
\text { (27) Heliot: This one? } \\
\text { (28) Denis: No, yes } \\
\text { (29) Irving: Then, it would be this one (pointing to option 2), because it is repeated like } \\
\text { this but it has a different figure on top } \\
\text { (30) Heliot: Well then, that is better } \\
\text { (31) Denis: This is better, this one (pointing to option 1), because look, this goes with } \\
\text { this, here on top, this with the same figure, and here there's a circle missing, a circle } \\
\text { having the same figure than here on top } \\
\text { (32) Heliot: Yes } \\
\text { (33) Irving: Put number one } \\
\text { (34) Denis writes ontion } 1 \text { correct }\end{array}$ \\
\hline
\end{tabular}


of 18 arguments in the pre-test and 22 in the post-test; again, not a noticeable difference. In contrast, the experimental group produced a total of 42 arguments in the pre-test and 106 in the post-test (almost triple). Furthermore, a more thorough analysis of these latter arguments revealed that they not only increased in quantity but also in quality: they were more clear, coherent, explicit, precise and concise in the post-test.

We next wanted to see if these improvements in the quality of the talk of the experimental children's discussions for solving reasoning problems also occurred for the psycholinguistic domain, where processes of oracy and literacy are involved, and which are particularly relevant for the school context.

\subsection{Original results for the oral part of the 'group test of textual integration'}

In relation to the oral part of the 'group test of textual integration', we analysed initially to what extent the two experimental and two control triads filmed used exploratory talk during the pre- and post-tests. The analysis was carried out mainly by searching for evidence of the presence of arguments in the transcripts of each triad for each test. This was done given that, as described above, arguments are an essential element present when exploratory talk is used.

The analysis of all the transcripts for both the pre- and post-tests and for both treatment groups revealed that there were no arguments present in any of them. This suggested that children in general did not use exploratory talk to solve this task. Therefore, using the system of analysis to characterise the three types of talk proposed by Mercer (ibid.), the talk of the two treatment groups in both tests could be characterised as been mainly cumulative. However, a further discursive analysis of all the transcripts suggested that, while the talk of the control group did not seem to vary much between tests, that of the experimental group appeared to become more coordinated and sophisticated in the post-test in comparison to the pre-test. This indicated that changes other than the use of arguments had actually taken place. For that reason, in order to analyse these apparent changes in more detail, we used a second approach, that of the ethnography of communication. This approach seemed more suitable to shed light on the different goals pursued by the pupils within the task and thus could provide us with a description of the way pupils created a shared understanding from their own perspective.

We next review briefly this approach and then present some of the results of using it to analyse further the oral data of the 'group test of textual integration'.

\subsection{The ethnography of communication}

For our further analysis of children's discourse we drew upon the ethnography of communication, and in particular on the description of the units of analysis proposed originally by Hymes (1972) such as communicative acts, events, and situations. In particular, we followed the methods developed more recently by Fernández (2004) based on Hymes. This allowed us to carry out a more in depth microgenetic analysis of how each triad collaborated and discussed together to produce their summary, comparing their performance in the pre- and the post-test.

Ethnographers of communication (e.g. Hymes, 1974; Saville-Troike, 2003) are interested in studying the ways in which language is determined culturally. In this respect, researchers in this field have as their main goal the identification of culture and the rules of speaking that are followed in a given community. According to Hymes (1972), the founder of this approach, language is constituted in social acts and is also a cultural product, a tool for members of a social group to communicate with each other. Moreover, for Hymes (ibid.), speakers can use different channels or forms of expression, which are constitutive of social acts that take place within a discursive or speech community.

Communicative competence is a central concept addressed in the ethnography of communication. Saville-Troike (2003) claims that a theory of communicative competence involves the social and cultural knowledge speakers are presumed to have, which enable them to use and interpret linguistic forms. With the purpose of studying the communicative competence of speakers in a given activity, Hymes (1972) has defined the existence of a nested hierarchy of units of analysis that he called: communicative (or speech) situation, communicative event, and communicative act. Thus, in this hierarchy, communicative acts are part of communicative events, which are, in turn, part of communicative situations. More specifically, a communicative situation is 'the context within which communication occurs'. It is not always subject to a given location, and maintains a 'general configuration of activities, the same overall ecology within which communication takes place, although there may be great diversity in the kinds of interaction which occur there' (Saville-Troike, 2003, p. 23). Examples include ceremonies, court trials, fights, holiday parties, hunts, lovemaking, and a lesson in a school. 
According to Hymes, communicative situations are composed of speech and other kinds of events. They are not themselves subject to rules of communication, although rules of communication may refer to these situations as contexts (Fasold, 1990, p. 42). Examples of communicative events are categories of talk such as conversations, lectures, or formal introductions. However, some events are not as clearly defined with social labels, and in this respect their identification constitutes a fundamental part of doing ethnography of communication. At the same time, communicative events are composed of communicative acts. The latter are identified by its interactional function, and may be either verbal or non-verbal. It gets its status from the social context as well as from the grammatical form and intonation, and can be constituted by more than one utterance.

\subsection{Results of the talk around texts using the ethnography of communication}

Drawing on the ethnography of communication, the transcripts of the conversations of the four selected triads (two experimental and two control) while they were jointly discussing and writing their summary were codified according to the goal being pursued, in terms of communicative acts, events, and situations. We codified the different goals children pursued and assigned a label to the different communicative events and acts so that we could understand the way they approached the task for constructing the summary, analysing how they used language in their conversations around the text.

The results of the above analyses are very complex. For the sake of brevity, in Table 2 we present, as a way of example of our results, a summary of the analysis of the transcripts of the talk produced by experimental triad number 1 , around the construction of their summary during the pre-test. This context corresponds to the general communicative situation (we later contrast these results to the ones obtained for the same triad during post-test).

In the pre-test, we found three communicative events and nine communicative acts. The most relevant characteristic of them was that children carried out the activities individually, after simply dividing them out among themselves and each doing one part, but without any evidence of coordination, negotiation or collaboration. In addition, there was a noticeable indiscriminate selection and copying of some of the information from each note, writing these pieces without relation to each other. Thus, the students were not very strategic in the way that they approached the task of constructing their summary.

Next, in Table 3, we present a summary of the analysis of the transcripts of the talk produced by the same experimental triad (1) around the construction of their summary, this time for the post-test.

In this post-test communicative situation we identified 7 communicative events and 45 communicative acts. In contrast to the pre-test, it is striking the increment of communicative acts within each of the events. Since the beginning of the interaction, there is more symmetry in the distribution of the tasks, and the work is eminently carried out in a joint, cooperative and co-constructive fashion. Whereas in the pre-test pupils mainly copied and dictated from the original sources individually, in the post-test, more than the dictation of information, the situation was much more collaborative

Table 2

Summary of analysis of transcripts from dialogues by experimental triad 1, during the pre-test

\begin{tabular}{|c|c|c|}
\hline Communicative event & Communicative acts & Comments \\
\hline (1) Planning (turns 1-3) & $\begin{array}{l}\text { (1) Distribution of task } \\
\text { (2) Goal identification } \\
\text { (3) Accepting activities to be done }\end{array}$ & $\begin{array}{l}\text { Children are initiating the test by agreeing on how to go } \\
\text { about it. Division of labour is predominantly } \\
\text { individualistic }\end{array}$ \\
\hline (2) Reading and selection (turns 4-6) & $\begin{array}{l}\text { (3) Communicative acts of } \\
\text { indiscriminate selection }\end{array}$ & $\begin{array}{l}\text { Each child reads one of the notes from the test and gives } \\
\text { an opinion on which part of the paragraph assigned to } \\
\text { them is to be selected. They each repeat the reading of } \\
\text { the paragraph but without making a strategic selection } \\
\text { of which information is the most important for the } \\
\text { summary }\end{array}$ \\
\hline (3) Reading, dictation and writing (turns 7-21) & $\begin{array}{l}\text { (1) Goal identification } \\
\text { (2) Individual copy } \\
\text { (3) Indiscriminate copy }\end{array}$ & $\begin{array}{l}\text { Laura organizes this communicative event by identifying } \\
\text { the goal and supervising the reading and dictation of } \\
\text { each section. Each child makes an indiscriminate copy } \\
\text { of the section they selected for reading }\end{array}$ \\
\hline
\end{tabular}


Table 3

Summary of analysis of transcripts from dialogues by experimental triad 1 , during the post-test

Communicative event Communicative act Comments

(1) Reading and selection by summarising together (turns 1-12)

(2) Dictation (turns 13-24)

(3) Reading and selection by summarising together (turns 25-40)
(1) Reading
(2) Goal identification
(3) Ask for opinions
(4) Selection with suppression
(5) Ask for opinions
(6) Selection with paraphrasing
(7) Reaching of consensus

(1) Dictation

(2) Writing

(1) Reading
(2) Asking for opinions

(3) Selection with paraphrasing

(4) Clarification of the goal

(5) Asking for opinions

(6) Selection with paraphrasing and construction

(7) Self-regulation (monitoring)

(8) Joint elaboration

(4) Dictation (turns 41-46)

(5) Reading and selection by summarising together (turns 47-80)

(6) Dictation (turns 81-109)
(1) Joint elaboration

(1) Reading

(2) Goal clarification

(3) Reading

(4) Selection of information

(5) Reading

(6) Goal clarification

(7) Reading

(8) Asking for opinions

(9) Selection of information

(10) Asking for opinions

(11) Selection with suppression

(12) Joint elaboration

(13) Reading

(14) Asking for opinions

(15) Selection with suppression

(16) Asking for opinions

(17) Joint elaboration

(18) Reaching of consensus

(1) Dictation and copy

(2) Joint elaboration
From the beginning of the test children work together and they do not divide the notes between them as in the pre-test. One child reads the three notes and the others listen. When they select the information to be included they ask for the opinion of the three children. For selecting the relevant information they use strategies such as suppression and paraphrasing

In this event, there are cycles of dictation and selected writing of information from the first note

This is a relevant event where the three children are jointly working on the second note (from an encyclopedia). They re-read the note, and discuss together about the appropriateness of information they have selected so far. In line 28 , one of the participants asks the experimenter if they can 'construct' on the information from the text (e.g. by inferring and using their own words). Children exhibit efforts to paraphrase and construct new information not explicit in the original texts

In line 30 , they jointly paraphrase and construct, and take turns in completing the phrases. They elaborate the summary jointly

This event, even if it included dictation, was also characterised by a joint elaboration of the phrases selected to be included in the summary

During this event children are working with the third note: an interview. To summarise it is necessary to change the linguistic register, from an interview to reported speech or a narrative. Children realize and comment on the difficulty of this task (line 56), given that at the beginning of the event there are two communicative acts of goal clarification, as well as several attempts to transform the original information. This difficulty is reflected in the fact that this is one of the longest events with 18 communicative acts

During this event dictation prevails and even though children had managed orally to select the information with suppression, paraphrasing and construction, as children write they come closer to the information as it appears originally in the text. Still, at the end of this event children elaborate jointly the phrases for the summary 
Table 3 (Continued)

\begin{tabular}{lll}
\hline Communicative event & Communicative act & Comments \\
\hline $\begin{array}{l}\text { (7) Joint elaboration of a title } \\
\text { (turns 110-117) }\end{array}$ & (1) Asking for opinions & All three children participate in the creation of a title for the \\
& (2) Giving opinions (two & three sections of the task, providing different options and \\
options) & eventually reaching consensus \\
(3) Giving opinions & \\
(4) Selection of one option & (5) Asking for opinions \\
& (6) Selection of an option \\
& (7) Reaching of consensus \\
\end{tabular}

and evolved through a series of communicative events of joint discussions, elaborations and constructions. These events included communicative acts such as taking turns, asking for and providing opinions, generating alternatives, reformulating and elaborating on the information being considered, coordinating and negotiating perspectives, and seeking agreement, among others. The prevailing approach for creating the summary was not the indiscriminate copying that they used in the pre-test, but a much more strategic intervention which included processes of suppression of irrelevant information, paraphrasing and in some cases construction of new, inferred information. That is, these children managed to establish a distance from the text and showed a much more elaborated strategic intervention. As a result, the summary they constructed had better quality than that produced in the pre-test.

The data described above in terms of the improvements in the quality of the discussions and general performance shown by experimental triad number 1 between the pre- and post-tests are in general fairly representative of the performance of the other experimental triad which was also filmed for this task. In contrast, the two control triads performed very similarly in the pre- and post-test, not showing a noticeable improvement. Their performance for both tests was quite similar to the one described above for experimental triad number 1 during pre-test.

The aims of this study do not include a report of the results for the written part of the 'group test of textual integration'. However, as a way of summary to complement the data reported so far, we would like to mention than in general, for the larger study with all 120 children, results showed that, after implementation of the educational program 'Learning Together', the quality of the summaries produced by the experimental group was significantly better than that of the control group in all aspects considered. These included the main ideas represented in the summaries, as well as their organization, coherence and their level of abstraction (see Mazón et al., 2005, for a full account of these results).

\subsection{Discussion}

In this article, we have used two approaches to the analysis of discourse in order to characterise and compare the quality of the strategies children followed for working together in two different tasks. The first approach, following the exploratory talk method proposed by Mercer and Wegerif allowed us to identify very accurately how the experimental children used language to think together and make their reasoning explicit by using exploratory talk in order to solve the matrices of the RSPM test after being trained to use this kind of talk.

In the data presented in Section 1.3 on these results, it is apparent that the performance of the experimental and control groups in the pre-test are different to a certain extent. In particular, the control group performed somewhat lower than the experimental group in this test. It could be argued that this initial advantage exhibited by the experimental group may in fact explain to a certain degree their having gained substantially more between tests than the control group. However, in other previous studies where we also trained groups of experimental children to use exploratory talk following a very similar approach to that of the present study, we found significant gains in these groups in contrast to controls, in spite of the fact that the initial level of the two groups was much more even (see Fernández, Wegerif, Mercer, \& Rojas-Drummond, 2001; Rojas-Drummond, Fernández, \& Vélez, 2000). This leads us to sustain that it was indeed the intervention programme which promoted exploratory talk which was mainly responsible for the effects found in the present study. Furthermore, this claim can also be supported by the very consistent and strong effects found in previous studies carried out by Mercer and Wegerif in the UK (Mercer et al., 1999; Wegerif et al., 1999), in relation to significant gains achieved by groups of children after been trained to use exploratory talk, following also similar procedures. In addition, cross-cultural comparisons made on the results obtained by the British and Mexican teams on 
the effects of promoting exploratory talk in children of both countries show remarkable and consistent similarities in spite of evident cultural variations (see Rojas-Drummond \& Mercer, 2003; Wegerif, Perez Linares, Rojas-Drummond, Mercer, \& Velez, 2005).

Following the claim that the ground rules of exploratory talk can be applied not only to the process of solving matrices, but also to other domains, we further assessed to what extent exploratory talk could be used by the same children in a more open ended task such as that of discussing, reading and writing a summary in groups.

Despite the fact that the type of talk of the experimental group in this last task after training could not be characterised as exploratory given that the reasoning was not made explicit in the way group work was carried out, that is, they did not produce arguments, we noticed that other changes in the quality of their talk had apparently taken place. At the same time, the quality of the summaries the experimental children produced increased significantly in the post-test. Therefore, in order to analyse these apparent changes in children's talk in more detail, as well as to reveal how the use of language in social interaction could have contributed to an improvement in the quality of the summaries produced after training, we drew on the ethnography of communication to reveal the insider's perspective in the way they tackled this task.

Following this second approach, we found that both the number and quality of communicative events and acts increased in the post-test. Thus, the use of language revealed substantially different goals and complexity of acts in each event, being much more coordinated and collaborative than in the pre-test. We hypothesise that this is related to the significant improvements in the quality of the joint summaries they produced after the intervention programme.

We next address more directly the central question that we put forward in the introduction: is it possible to characterise productive educational talk in general or is the quality of talk too closely related to the task for such an attempt to be useful? Engaging in explicit and accountable reasoning, with claims and challenges and warrants, was useful for success in joint solving of the reasoning test where the aim was to find the single correct underlying essentially mathematical pattern that united a series of pictures. In contrast, explicit reasoning was not found so useful for the more open-ended and 'divergent' task of constructing together an integrated summary that met certain criteria of quality. While solving the reasoning task involved creativity, it was creativity in the tightly bound context of a convergent mathematical problem with only one correct answer. Constructing a summary after reading three related texts which differed in genre is a more evidently creative task and it is not obvious that explicit reasoning always supports creativity. Indeed, there are some suggestions from studies of classroom talk that in some cases it may hamper co-construction by preventing the expression of contributions that can not be explicitly justified (Wegerif, 2005). However, there is evidence that the ground rules of exploratory talk, other than explicit reasoning, support a dialogic 'space of reflection' in which multiple alternatives are expressed and selected (Wegerif, in press).

Beyond the contrasts specified above, however, an overall, higher order discursive analysis carried out for both tasks (which took into account the patterns obtained by analysing the uses of exploratory talk as well as those resulting from applying the ethnography of communication) revealed that, in spite of some differences such as the presence or absence of arguments, the uses of discourse by the experimental children to solve both tasks after training shared many commonalities. In particular, the exploratory talk used to solve the reasoning task and the kind of talk that succeeded in the collaborative writing task shared many communicative acts such as taking turns, asking for and providing opinions, generating alternatives, reformulating and elaborating on the information being considered, coordinating and negotiating perspectives and seeking agreements. This supports the argument that it is possible and even fruitful to propose a single over-arching framework to account for productive discussion in education of which these two kinds of talk are task-related versions.

To account for such a single over-arching framework, we propose to adopt the concept of 'co-constructive talk' as an inclusive term to characterise the joint efforts of coordination, negotiation and collaboration in various group work activities. This new type of talk is required partly because the contrast between exploratory talk and cumulative talk depends upon the criterion of explicit reasoning, which the findings of this study show to be a task dependent criterion. At the same, the two methodological approaches used in this study (i.e. the types of talk proposed by Mercer and Wegerif and the Ethnography of Communication), seem to have an underlying shared focus on finding common mechanisms used by participants to construct meaning jointly in any dialogue.

Following an ethno-methodological perspective, which informs analytical methods in conversation analysis, discursive psychology and interactional sociolinguistics, researchers have looked at the process of co-construction of meaning in group work as a joint interactional accomplishment. In this respect, meaning is negotiated through talk and other non-verbal cues indexing the construction of categories, which are embedded in the situated and dialogical 
nature of social action (e.g. Goodwin, 1995; Mäkitalo \& Säljö, 2002; Roschelle, 1992; Säljö, 1999). We believe that the concept of co-construction in general, and 'co-constructive talk' in particular, can also be productively employed to characterise a much wider scope of collaborative activities and discussions children display when working together to solve problems of very different nature and in many educational contexts, well beyond the ones analysed in the present study.

Our data showed that a co-constructive style of interaction and discourse could be employed successfully by the experimental children after training to tackle problems of a different nature. But this style was by no means rigid; on the contrary, it was flexibly adapted to the task and context in which interaction was embedded. In this respect, our data supports a situated view of cognition and communication as proposed by a sociocultural perspective (e.g. Lave \& Wenger, 1991; Light \& Butterworth, 1992; Rogoff, 2003; Rogoff \& Lave, 1984; Rogoff, Turkanis, \& Bartlett, 2001; Säljö, 1997). The same children could readily use exploratory talk to solve a convergent task like the RSPM test after training, but used a somewhat different collaborative style of talk which did not make explicit their reasoning or arguments in a more creative, open ended or divergent task which involved discussing, reading and writing a summary. So, they adapted their collaborative and discursive strategies to the context and task in hand. However, at the same time, as discussed above, the type of talk they used in both tasks, beyond certain differences, also shared many communicative acts of joint coordination and collaboration, which we encompassed in the broader concept of co-constructive talk.

Within the above theoretical framework, we could conceptualise exploratory talk as a particularly effective and sophisticated type of educated talk or 'social mode of thinking', which represents one specific form of co-constructive interaction. As shown by a wealth of recent research (some reviewed under Section 1.1), this type of talk can be very fruitfully applied to a wide range of academic and other contexts which benefit from reasoning being made explicit. However, for other contexts, explicit reasoning might not be so functional or necessary, as became evident from our data. Finding the scope and range of functionality of different styles of co-constructive interaction, and for different situations and domains, should, in our opinion, be a central agenda of further studies of collaboration, discourse and knowledge construction in various educational settings. This endeavour would in turn provide a set of guidelines for how to promote productive styles of interaction and communication embedded in various educational practices. A programme of activities for promoting exploratory talk in particular is presented in Dawes et al. (2000) (see also Wegerif \& Dawes, 2004). Another attempt to provide such guidelines for promoting oral and literate school practices, including functional uses of ICT is being developed at present and a summary of this proposal can be found in RojasDrummond, Albarran, Vega, Zuniga, and Velez (2006). Similar efforts still need to be developed further for different knowledge domains and educational contexts.

\section{References}

Dawes, L., Mecer, N., \& Wegerif, R. (2000). Thinking together: A programme of activities for developing thinking skills at KS2. UK: Questions.

Edwards, D., \& Mercer, N. (1987). Common knowledge. London: Methuen and Routledge.

Fasold, R. (1990). Sociolinguistics of language: Vol. II, Oxford: Basil Blackwell.

Fernández, J. M. (2004). The Appropriation and Mastery of Cultural Tools in Computer Mediated Collaborative Literacy Practices. Unpublished PhD. Milton Keynes, UK: The Open University.

Fernández, M., Wegerif, R., Mercer, N., \& Rojas-Drummond, S. M. (2001). Re-conceptualizing "scaffolding" and the zone proximal development in the context of symmetrical collaborative learning. Journal of Classroom Interaction, 36(2), 40-54.

Gee, J. P. (1999). An introduction to discourse analysis: Theory and method. London: Routledge.

Goodwin, C. (1995). Co-constructing meaning in conversations with an aphasic man. Research on Language and Social Interaction, 28(3), 233-260.

Habermas, J. (1981). The problem of understanding meaning in the social sciences. The theory of communicative action: Vol. 1, Cambridge: Polity Press, pp. 102-141.

Habermas, J. (1990). Discourse ethics: notes on a program of philosophical justification. In Moral consciousness and communicative action. Cambridge: Polity Press, pp. 43-115.

Hicks, D. (1995). Discourse, learning and teaching. In M. W. Apple (Ed.), Review of research in education: 21, (pp. 49-95). New York: American Educational Research Association.

Hymes, D. (1972). Models of interaction in language and social life. In J. J. Gumperz \& D. Hymes (Eds.), Directions in sociolinguistics: the Ethnography of communication (pp. 35-71). London: Basil Blackwell.

Hymes, D. (1974). Foundations in sociolinguistics. London: Tavistock Publications Limited.

Kruger, A. (1993). Peer collaboration: conflict, cooperation or both? Social Development, 2(3).

Lave, J., \& Wenger, E. (1991). Situated learning: Legitimate peripheral participation. Cambridge: Cambridge University Press.

Light, P., \& Butterworth, G. (Eds.). (1992). Context and cognition, ways of learning and knowing. New York: Harverster. 
Light, P., Littleton, K., Messer, D., \& Joiner, R. (1994). Social and communicative processes in computer-based problem solving. European Journal of Psychology of Education, 9, 93-110.

Mäkitalo, A., \& Säljö, R. (2002). Talk in institutional context and institutional context in talk: Categories as situated practices. Text, 22(1), 57-82.

Mazón, N., Rojas-Drummond, S. M., \& Vélez, M. (2005). Efectos de un programa de fortalecimiento de habilidades de comprensión de textos en educandos de primaria. Revista Mexicana de Psicología, 22(1), 91-102.

Mercer, N. (1995). The guided construction of knowledge: Talk amongst teachers and learners. Clevedon: Multilingual Matters.

Mercer, N. (2000). Words and minds: How we use language to think together. London: Routledge.

Mercer, N., Wegerif, R., \& Dawes, L. (1999). Children's talk and the development of reasoning in the classroom. British Educational Research Journal, 25(1), 95-112.

Rogoff, B. (2003). The cultural nature of human development. London: Oxford University Press.

Rogoff, B., \& Lave, J. (Eds.). (1984). Everyday cognition: It's development in social context. Cambridge: Harvard University Press.

Rogoff, B., Turkanis, C., \& Bartlett, L. (Eds.). (2001). Learning together: Children and adults in a school community. London: Oxford University Press.

Rojas-Drummond, S. M., Fernández, M., \& Vélez, M. (2000). Habla Exploratoria, Razonamiento Conjunto y Solución de Problemas en Niños de Primaria. En La Psicología Social en México: Vol. VIII, México: Asociación Mexicana de Psicología Social.

Rojas-Drummond, S. M., \& Mercer, N. (2003). Scaffolding the development of effective collaboration and learning. International Journal of Educational Research, 39, 99-111.

Rojas-Drummond, S. M., Pérez, V., Vélez, M., Gomez, L., \& Mendoza, A. (2003). Learning for reasoning among Mexican primary school children. Learning and Instruction, 13(6), 653-670.

Rojas-Drummond, S. M., \& Peón, M. (2004). Exploratory talk, argumentation and reasoning in Mexican primary school children. Language and education, 18(6), 539-557.

Rojas-Drummond, S. M., Albarran, D., Vega, G., Zuniga, M., \& Velez, M. (2006). Learning together: The creation of communities of inquiry supported by ICT. MirandaNet e-Journal (http://www.mirandanet.ac.uk/internat/mexico.htm).

Roschelle, J. (1992). Learning by collaborating: Convergent conceptual change. The Journal of the Learning Sciences, 2(3), $235-276$.

Säljö, R. (1997). Learning and discourse: A sociocultural perspective. Leicester: British Psychological Society.

Säljö, R. (1999). Learning as the use of tools: A sociocultural perspective on the human-technology link. In K. Littleton \& P. Light (Eds.), Learning with computers: Analyzing productive interaction (pp. 144-161). London: Routledge.

Saville-Troike, M. (2003). The ethnography of communication. Oxford: Blackwell Publishing.

Vygotsky, L. S. (1978). M. Cole, V. John-Steiner, S. Scribner, \& E. Souberman (Eds.), Mind in society: The development of higher psychological processes: Cambridge, MA: Harvard University Press.

Vygotsky, L. S. (1987). Thinking and speech (S. Sochinenii, Trans.). In Rieber, R. W., \& Carton, A. S. (Eds.), The collected works of L. S. Vygotsky: Problems of general psychology: Vol. 1 (pp. 39-285). New York: Plenum.

Wegerif, R. (1996). Using computers to help coach exploratory talk across the curriculum. Computers and Education, 26(1-3), 51-60.

Wegerif, R. (2005). Reason and creativity in classroom dialogues. Language and Education, 19(3), 223-237.

Wegerif, R. (in press). Reason and dialogue in education. In van Oers, B., Elbers, E., van der Veer, R., Wardekker, W. (Eds.), The Transformation of Learning. Cambridge, UK: Cambridge University Press.

Wegerif, R., \& Dawes, L. (2004). Thinking and learning with ICT: Raising achievement in primary schools. London: Routledge Falmer.

Wegerif, R., \& Mercer, N. (1996). Computers and reasoning through talk in the classroom. Language and Education, 10(1), $47-64$.

Wegerif, R., \& Mercer, N. (1997). A dialogical framework for researching peer talk. In R. Wegerif \& P. Scrimshaw (Eds.), Computers and talk in the primary classroom (pp. 49-61). Clevedon: Multilingual Matters.

Wegerif, R., Mercer, N., \& Dawes, L. (1999). From social interaction to individual reasoning: an empirical investigation of a possible sociocultural model of cognitive development. Learning and Instruction, 9(6), 493-516.

Wegerif, R., Perez Linares, J., Rojas-Drummond, S., Mercer, N., \& Velez, M. (2005). Thinking together in the UK and Mexico: Transfer of an educational innovation. Journal of Classroom Interaction, 40(1), 40-48.

Wertsch, J. V. (1998). Mind as action. New York: Oxford University Press. 